\title{
Cirrosis hepática
}

\section{Liver cirrhosis}

\author{
Alfredo Pinzón-Junca • Bogotá, D.C. (Colombia)
}

DOI: https://doi.org/10.36104/amc.2019.1637

El lenguaje médico busca la claridad y precisión en sus términos, para evitar confusión y ambigüedad. Sin embargo, en ocasiones la tradición perpetúa algunas expresiones que en la actualidad pueden verse como inapropiadas. Es el caso del sintagma cirrosis hepática.

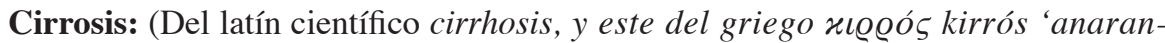

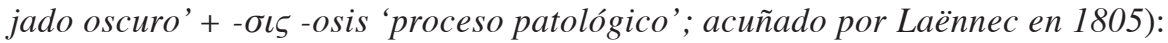

1) f. Med. Enfermedad caracterizada por una lesión que se desarrolla en las vísceras, especialmente en el hígado, y consiste en la induración de los elementos conjuntivos y atrofia de los demás.

2) Alteración indurativa de un órgano por proliferación de tejido fibroso y atrofia de las células parenquimatosas.

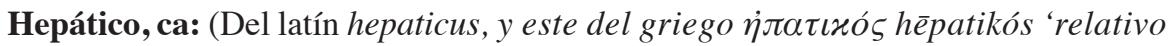
al hígado', derivado de $\dot{\eta} \pi \alpha \tau o \zeta$ hēpatos 'hígado'):

1) adj. Del hígado o relacionado con él.

2) adj. Que padece del hígado.

Por consiguiente, la palabra cirrosis aplica para cualquier proceso de afección y cicatrización de órganos parenquimatosos como el hígado, el riñón y el pulmón. No obstante, tácitamente la jerga médica ha venido reservando este término exclusivamente para la enfermedad del primero, por lo que la mayoría considera redundante decir cirrosis hepática, y prefieren más bien aclarar su posible tipo o etiología, mediante expresiones como cirrosis alcohólica, cirrosis autoinmune, cirrosis biliar, cirrosis postviral, etc.

\section{Fuentes:}

- Diccionario de la Real Academia Española de la Lengua, disponible en: www.rae.es

- Real Academia Nacional de Medicina. Diccionario de Términos Médicos. Editorial Médica Panamericana. 2012

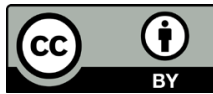

* Envíe sus inquietudes, sugerencias o comentarios a: contacto@actamedicacolombiana.com - alfpin@hotmail.com Dr. Alfredo Pinzón-Junca: Especialista en Medicina Interna y Psicoanálisis. Hospital Universitario de La Samaritana y Hospital Simón Bolívar. Coordinador del Consejo de Acreditación y Recertificación de la ACMI ${ }^{\circledR}$. Bogotá, D.C. (Colombia).

E-mail: alfpin@hotmail.com

Recibido: 17/IX//2019 Aceptado: 19/IX/2019 